\title{
Meconium pseudocyst associated with congenital CMV infection
}

\author{
Authors: \\ Sucari Vlok ${ }^{1}$ \\ Vicci du Plessis ${ }^{2}$

\section{Affiliations:} \\ ${ }^{1}$ Division Radio-Diagnosis, \\ Stellenbosch University, \\ Tygerberg Hospital, South \\ Africa \\ 2Department Radiology, \\ Grey's Hospital, South Africa

\section{Correspondence to: \\ Sucari Vlok \\ Email: \\ sucarivlok@gmail.com} \\ Postal address: \\ PO Box 19010, Tygerberg \\ Hospital, Cape Town 7505, \\ South Africa \\ Dates: \\ Received: 09 June 2015 \\ Accepted: 14 Oct. 2015 \\ Published: 09 Dec. 2015 \\ Republished: 15 Dec. 2015 \\ How to cite this article: \\ Vlok SSC, Du Plessis V. \\ Meconium pseudocyst \\ associated with congenital \\ CMV infection. S Afr J Rad \\ 2015;19(2): Art. \#893, \\ 3 pages. http://dx.doi. \\ org/10.4102/sajr.v19i2.893

\section{Note:} \\ Manuscript republished \\ under correct section \\ from 'Original Research' \\ to 'Case Report'.

\section{Copyright:} \\ C 2015. The Authors. \\ Licensee: AOSIS \\ OpenJournals. This work is \\ licensed under the Creative \\ Commons Attribution \\ License.
}

\section{Read online:}

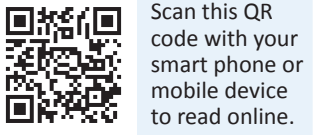

Meconium pseudocyst is a rare complication of fetal bowel perforation in utero, following extravasation and localised containment of meconium within the intra-peritoneal cavity.

\section{Introduction}

Meconium pseudocyst is a rare, perinatal complication of intra-uterine fetal bowel perforation, with very few cases reported in the literature. Intestinal obstruction and perforation with subsequent intra-peritoneal extravasation of meconium causes a sterile, chemical inflammatory response and the formation of dystrophic calcifications. Sporadically, meconium peritonitis may result in fixation of the inflamed bowel loops, forming a contained collection with a membranous wall, into which meconium may leak continuously from the perforation site. . $^{1,3,3,4}$

The presence of a meconium pseudocyst indicates complex peritonitis which necessitates specialist evaluation, delivery at a tertiary care facility and, in most cases, neonatal surgical intervention. ${ }^{2}$

\section{Case report}

A 25-year-old HIV-positive pregnant woman (G3P2) was referred for antenatal ultrasound (US) at 28 weeks, which revealed a large, cystic intra-abdominal mass within the fetus, with an irregularly calcified rim and internal echoes (Figure 1). There was associated polyhydramnios and an oedematous placenta. The patient presented at the obstetric unit 4 weeks later with premature rupture of the membranes. The baby was born prematurely via a normal vertex delivery at 32 weeks.

A computed tomography (CT) scan performed on the day of birth revealed a large, cystic intraabdominal mass with a calcified rim, displacing adjacent abdominal organs (Figure 2). Subsequent laparotomy was performed with extensive adhesiolysis to free the bowel, and biopsies obtained for histological evaluation, which confirmed meconium pseudocyst. Neonatal infection screening revealed the presence of cytomegalovirus (CMV) infection.

\section{Discussion}

Meconium peritonitis is a sterile, chemical inflammatory response, occurring as a result of bowel perforation proximal to a partial or complete obstruction in utero. If the perforation site is not sealed off properly, meconium continues to extravasate into the peritoneal cavity. $1,2,3,4,5$ Dystrophic peritoneal calcifications are present in $85 \%$ of cases and may form as early as 12 hours postperforation, ${ }^{2,3}$ but may only become visible radiologically after a few weeks. ${ }^{1}$ Occasionally, a contained, meconium-filled collection outlined by adhered bowel loops may form - a meconium pseudocyst. $1,2,3,4,5$

Meconium peritonitis is a rare entity, with an incidence of 1:35 000 live births, usually presenting during or after the 2 nd trimester of pregnancy. ${ }^{3}$ Various causes of meconium peritonitis exist, including intestinal atresia/stenosis, volvulus, intussusception, Meckel's diverticulum or peritoneal bands. ${ }^{1,2,3,4,5}$ A relatively strong association with cystic fibrosis is seen in between $8 \%-$ $40 \%$ of patients diagnosed with meconium peritonitis, in which meconium ileus with subsequent perforation is the most likely cause..$^{1,2,4}$ The association of meconium peritonitis with intra-uterine CMV and Parvovirus B19-infections is documented. ${ }^{4,5}$

Characteristic ante- and postnatal US findings include ascites, numerous scattered intraperitoneal calcifications, and bowel distention (a combination which is pathognomonic for meconium peritonitis), ${ }^{2}$ and polyhydramnios (secondary to bowel obstruction), ${ }^{1,2,3,4,5}$ 
Fluid and/or calcifications may also be present in the scrotum owing to a patent processus vaginalis (meconium periorchitis). A meconium pseudocyst may be isolated or multiple, and appears as a cystic mass with a thick, irregular
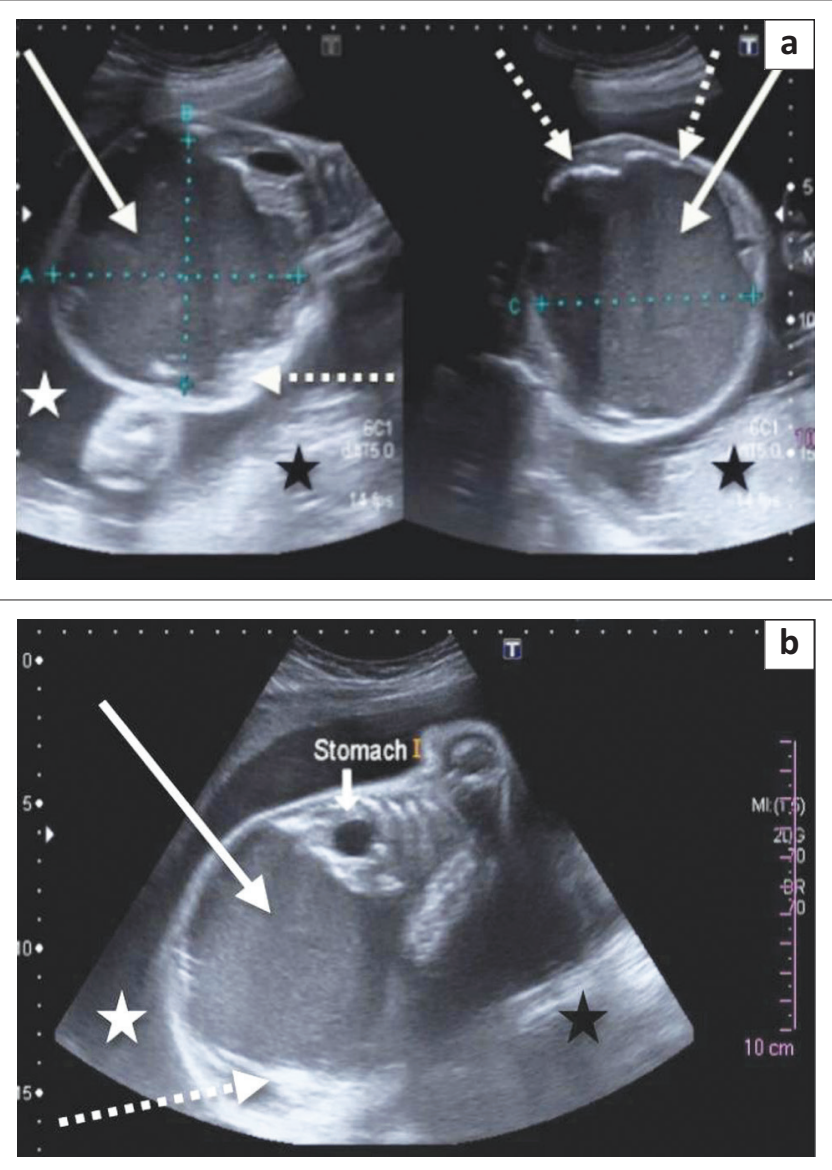

FIGURE 1: Transverse (a) and coronal (b) antenatal ultrasound at 28 weeks revealed a large, cystic intra-abdominal mass with internal echoes (white arrows) and calcified rim (dashed arrows) within the fetus. Note the polyhydramnios (white star) and oedematous placenta (black star). wall (with or without calcification) and content of variable echogenicity. ${ }^{2}$

Neonatal abdominal radiography reveals ascites, punctate or curvilinear peritoneal calcifications, and dilated bowel loops, with a soft-tissue mass in the presence of a meconium pseudocyst. ${ }^{1,2,3,4}$ The pseudocyst may displace intestinal loops, and demonstrate internal or rim calcification. $^{2}$

The differential diagnosis for the individual imaging features of meconium peritonitis is wide, and final diagnosis is dependent on the pathognomonic combination of findings. Associated conditions should be sought, such as trisomy 21, cystic fibrosis or in utero infection in the setting of echogenic bowel on pre/postnatal US. In the presence of intraabdominal calcifications, infection, gallstones or calcifying tumours should be considered (such as hepatoblastoma, teratoma or neuroblastoma). Most other intra-abdominal cysts do not calcify. ${ }^{2}$

Several surgical scoring systems exist, predicting the need for neonatal surgical intervention in patients with meconium peritonitis. The Zangheri scoring system (score $0-3$ ) has been found to be very accurate. ${ }^{4}$ The likelihood of surgical intervention in patients with simple peritonitis (score 0) - those patients found to have calcifications only - is low, and careful postnatal evaluation is advised. Patients with complex peritonitis (scores 1-3) need to be transferred to and delivered at a tertiary care facility, evaluated by a neonatologist and/or paediatric surgeon, and carefully followed up after birth, as the majority of these patients will require urgent neonatal surgery., Consequently, the prognosis of meconium peritonitis is better if diagnosis is made antenatally, particularly in cases of complex peritonitis. New advances in intra-uterine treatment, such as fetal paracentesis and/or pseudocyst

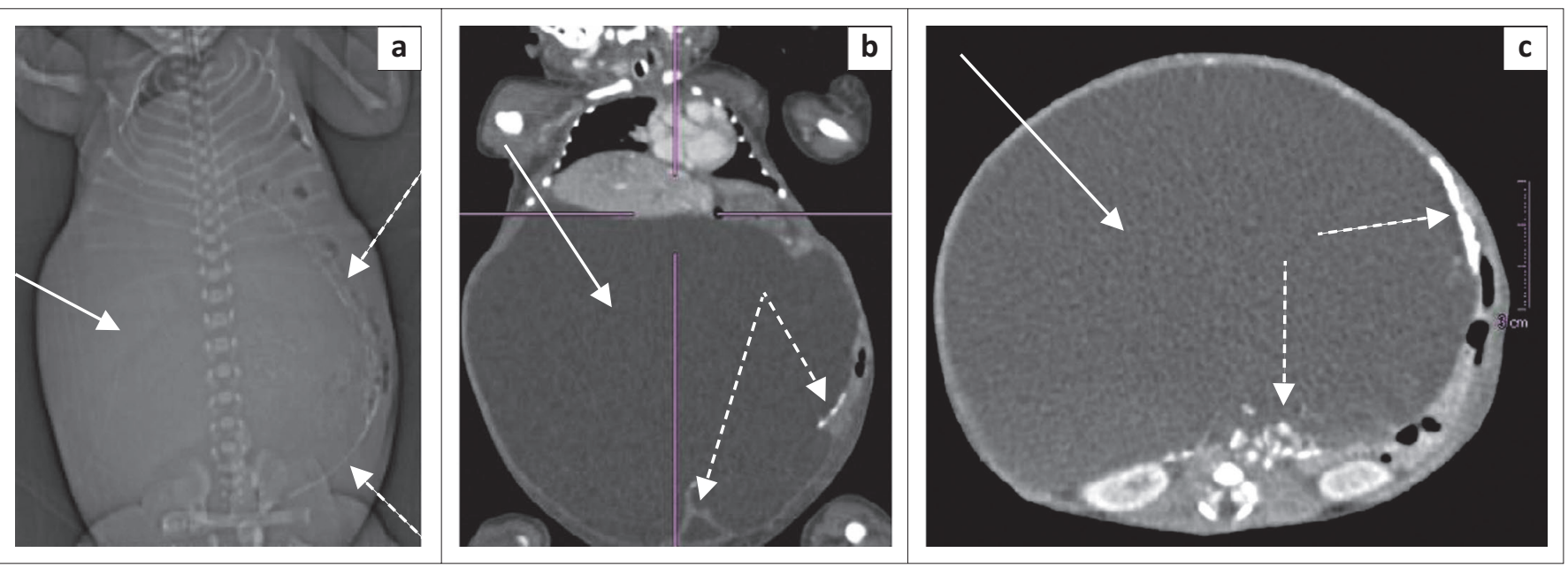

FIGURE 2: Topogram (a), coronal (b) and transverse (c) CT images of the abdomen on the day of birth revealed a large, cystic intra-abdominal mass (white arrows) with calcified rim (dashed arrows) displacing the internal organs, which radiologically confirmed the diagnosis of a meconium pseudocyst. The neonate tested positive for CMV infection at birth. 
drainage, and anti-inflammatory injection, are currently under investigation. ${ }^{2}$

\section{Conclusion}

Meconium pseudocyst is a rare entity. However, it is an indication of complex peritonitis where early imaging diagnosis is critical for timely specialist evaluation/ intervention and improved prognosis. In the HIV-positive population, CMV is an important aetiological consideration of meconium peritonitis, and further research into this association is warranted.

\section{Acknowledgements}

\section{Authors' contributions}

S.C. (Stellenbosch University) drafted the article. V.d.P. (Grey's Hospital) reviewed and edited the article.

\section{Competing interests}

The authors declare that they have no financial or personal relationships which may have inappropriately influenced them in writing this article.

\section{References}

1. Valladares E, Rodriguez D, Vela A, Cabré S, Lailla JM. Meconium pseudocys secondary to ileum volvulus perforation without peritoneal calcification: A case report J Med Case Rep. 2010;4:292. PMID: 20807399, http://dx.doi.org/10.1186/17521947-4-292

2. Woodward PJ. STATdx premier. Meconium peritonitis, pseudocyst. Salt Lake City: Amirsys; 2005-2014. c2005 [cited 2015 May 14-22]. Available from: http:// my.statdx.com

3. Dähnert W. Radiology review manual. 6th ed. Philadelphia: Lippincott Williams \& Wilkins; 2007; p. 856.

4. Saleh N, Geipel A, Gembruch U, et al. Prenatal diagnosis and postnatal management of meconium peritonitis. J Perinat Med. 2009;37:535-538. PMID: 19492926, http:// dx.doi.org/10.1515/JPM.2009.097

5. Pletcher BA, Williams MK, Mulivor RA, Barth D, Linder C, Rawlinson K. Intrauterine cytomegalovirus infection presenting as fetal meconium peritonitis. Obstet Gynecol. 1991;78:903-905. PMID: 1656350. 